\title{
CARACTERIZAÇÃO DE LAVOURAS CAFEEIRAS, UTILIZANDO TÉCNICAS DE GEOPROCESSAMENTO E SENSORIAMENTO REMOTO, NO MUNICÍPIO DE UMUARAMA - PR
}

\author{
Characterization of coffee crops using techniques of geoprocessing \\ and remote sensing in the city of Umuarama - PR
}

\author{
Kleber Trabaquini' ${ }^{1}$ Édison Miglioranza ${ }^{2}$, Valmir de França ${ }^{3}$, Osvaldo Coelho Pereira Neto ${ }^{3}$
}

\begin{abstract}
RESUMO
O sensoriamento remoto e o geoprocessamento são geotecnologias importantes no apoio ao levantamento de dados da agricultura, permitindo estudos e o entendimento das relações ambientais em que uma determinada cultura está inserida. Neste trabalho,objetivou-se, relacionar as variáveis físicas, como, altimetria, declividade e tipo de solo com o agrossistema cafeeiro existente no município de Umuarama-PR pelo uso de geotecnologias. Foi utilizada a imagem do satélite LANDSAT 5/TM (Thematic Mapper) com data de passagem em 02/07/2007 e o software SPRING 4.3.3. As bandas 3, 4 e 5 do sensor TM foram restauradas, resultando em imagens de $15 \mathrm{~m}$ de resolução espacial e, posteriormente, constituindo a composição colorida RGB, na sequência TM4, TM5, TM3, a qual foi empregada na identificação das lavouras cafeeiras por meio de interpretação visual. Para o estudo do relevo, foram utilizados dados da missão SRTM, os quais possibilitaram o conhecimento da altimetria e declividade da região. A imagem do sensor TM possibilitou a execução da classificação visual e consequente identificação das lavouras cafeeiras com alta precisão. Quanto ao relevo, verificou-se que aproximadamente $99 \%$ das lavouras cafeeiras estão localizadas entre 380 e 480 metros de altitude e que $90 \%$ destas estão situadas em declividades de até $8 \%$ de inclinação. Em relação aos solos, observou-se que $89 \%$ dos cafeeiros são cultivados sobre Latossolo Vermelho distrófico, de textura arenosa.
\end{abstract}

Termos para indexação: LANDSAT 5/TM, cafeicultura, geotecnologias, caracterização física.

\begin{abstract}
The remote sensing and geoprocessing are important geotechnologies in support of the survey data of agriculture, enabling studies and understanding of environmental relations in which a particular culture is insert. The objective of this work was to relate the physical variables, such as altimetry, slope and soil type with the coffee agrosystems in Umuarama-PR through the geotechnologies. The image of the LANDSAT 5/TM (Thematic Mapper) dated in 02/07/2007 and the software SPRING 4.3.3 were used for the image processing. The bands 3, 4 and 5 of the sensor TM were restored, which resulted in images of $15 \mathrm{~m}$ spatial resolution and, later, creating the RGB color composition, which was used to identify the coffee crops through visual interpretation. For the relief map study, the data of the SRTM mission were applied, which enabled us to know the altimetry and declivity of the region. The image of the TM sensor enabled the visual classification and the consequent identification of the coffee crops with high precision. As for the relief area, it was noticed that about $99 \%$ of the coffee fields are located between 380 and 480 meters of altitude and that $90 \%$ of them are located in declivity of up to $8 \%$ of inclination. About the soils, it was observed that $89 \%$ of the coffee fields are grown over distrofic Red Latosol, of sandy texture.
\end{abstract}

Index terms: LANDSAT 5/TM, coffee culture, geotechnologies, physical characterization.

(Recebido em 4 de maio de 2009 e aprovado em 28 de julho de 2010)

\section{INTRODUÇÃO}

A cultura do café já teve uma significativa contribuição no quadro produtivo agrícola no município de Umuarama. Porém, a fragilidade dessa espécie diante das frequentes geadas, do mercado enfraquecido e de problemas com algumas patologias, enfraqueceu a proposta de pequenas propriedades, transferindo para a pecuária, a atividade de maior expressão na região, atualmente com $60 \%$ da área total do município
(Nepomuceno \& Silva, 2009). Mesmo assim, alguns produtores ainda persistem na cultura cafeeira que movimentou a economia nacional, principalmente no final da década de 1960 e de 1970 , auxiliando no desenvolvimento e na economia dessa região. Atualmente, esse município apresenta 635 ha dessa cultura, segundo dados do Instituto Brasileiro de Geografia e Estatística IBGE (2007). Outro órgão do governo relata uma área de 600 ha da mesma cultura (Secretaria de Estado da Agricultura e Abastecimento - SEAB, 2007), ou seja,

${ }^{1}$ Universidade Estadual de Londrina/UEL - Cx. P. 6001 - 86055-900 - Londrina, PR - klebertrabaquini@yahoo.com.br

2Universidade Estadual de Londrina/UEL - Departamento de Agronomia - Londrina, PR

${ }^{3}$ Universidade Estadual de Londrina/UEL - Departamento de Geociências - Londrina, PR 
ocorrem divergências entre os dados, mesmo quando a metodologia empregada é a mesma.

Além do conhecimento da área ocupada por uma cultura agrícola de forma exata é necessário também o conhecimento prévio do meio ambiente, onde determinada cultura está inserida. Para isso, os Sistemas de Informação Geográfica (SIGs) e a aplicação do sensoriamento remoto podem auxiliar nesse reconhecimento, contribuindo no estudo da espacialização e atualização dos dados coletados e consequente gerenciamento racional das atividades agrícolas (Resende et al., 1995; Campos et al., 2004; Xavier et al., 2004).

Ippoliti-Ramilo et al. (1999) ressalta que os levantamentos de dados agropecuários a partir da aplicação do sensoriamento remoto aliado às técnicas de geoprocessamento, em comparação a outras formas de levantamento, têm como vantagens a rapidez e a precisão, além do baixo custo quando utilizado em larga escala. Para Epiphanio et al. (2002), pesquisas relacionadas à identificação de culturas agrícolas utilizam em sua grande maioria imagens de sensores ópticos de média resolução, sendo, principalmente, provenientes dos satélites da série Landsat, cuja boa resolução espectral auxilia na distinção entre os diversos tipos de vegetação, porém sempre tendo como auxílio informações obtidas a campo para melhor precisão.

Estudos envolvendo culturas agrícolas por sensoriamento remoto e geoprocessamento, assim como a separação de culturas utilizando imagens de satélite vêm sendo realizados por diversos pesquisadores, dentre eles, Epiphanio et al. (1996, 2002), Moreira et al. (2004), Sanches et al. (2005) e Borges et al. (2010), mostrando assim a aplicação dos dados de sensoriamento remoto e Sistemas de Informações Geográficas na agricultura. Informações sobre a distribuição de culturas agrícolas e as características dos ambientes onde essas lavouras estão localizadas são de extrema importância, possibilitando estruturar e viabilizar planejamentos agrícolas adequados para a região produtora.

É possível assim, com o advento das geotecnologias, realizar com precisão e eficácia estudos que venham a fornecer dados suficientes para o entendimento das relações ambientais em que a cultura cafeeira esta inserida, vindo a servir também como subsídio para futuras pesquisas dessa cultura. Desse modo, conduziu-se este trabalho, com o objetivo de relacionar as variáveis físicas, como, altimetria, declividade e tipo de solo com o agrossistema cafeeiro existente no município de Umuarama-PR, utilizando técnicas de geoprocessamento e sensoriamento remoto.

\section{MATERIAL E MÉTODOS}

A área de estudo abrange o município de Umuarama que possui uma área territorial de $1.225 \mathrm{~km}^{2}$, e está localizado na região noroeste do estado do Paraná, no Terceiro Planalto paranaense, na formação geológica Caiuá e no divisor de águas das bacias dos rios Piquirí, Ivaí e sub-bacia do Rio Paraná, entre as latitudes $23^{\circ} 26^{\prime} 11^{\prime \prime} \mathrm{S}$ e $23^{\circ} 58^{\prime} 22^{\prime \prime} \mathrm{S}$ e longitudes $53^{\circ} 10^{\prime} 22^{\prime \prime} \mathrm{W}$ e $53^{\circ} 40^{\prime} 36^{\prime}$ ' W (Figura 1). Em virtude da formação geológica, os solos dessa região são constituídos predominantemente por arenitos de frações médias a finas, com coloração variando de vermelhoarroxeado a vermelho-escuro (Maurina \& Bublitz, 2001).

O clima da região, conforme método de Köeppen é classificado como $\mathrm{Cfa}$, clima subtropical úmido mesotérmico. As temperaturas médias nos meses mais frios são inferiores a $18^{\circ} \mathrm{C}$ e nos meses quentes são superiores a $22^{\circ} \mathrm{C}$, com geadas pouco frequentes no inverno. A precipitação pluviométrica está entre 1200 a $1600 \mathrm{~mm}$, com tendência de concentração das chuvas nos meses de verão (Instituto Agronômico do Paraná - IAPAR, 2000).

Realizou-se a caracterização do agroecossistema cafeeiro pela aplicação do sensoriamento remoto e geoprocessamento, utilizando como apoio tecnológico o SIG, especificamente o software SPRING 4.3.3. Foi utilizada a imagem do satélite LANDSAT 5/TM (Thematic Mapper), cuja área de estudo foi abrangida pelo mosaico de duas cenas completas com $185 \mathrm{~km}$ de visada com as seguintes características: órbita/ponto, 223/76 e 223/77, com data da passagem em 02/07/2007. O registro da imagem foi realizado por meio da coleta de dezoito pontos de controle coletados a campo com GPS (Global Positioning System) de navegação, o qual apresentou um erro final dos pontos de controle de 0,48 pixel.

As bandas TM 3, TM 4 e TM 5 correspondentes aos comprimentos de onda 0.63 - $069 \mu \mathrm{m}$ (vermelho), 0.76 $0.90 \mu \mathrm{m}$ (infravermelho próximo) e 1.55 - $1.75 \mu \mathrm{m}$ (infravermelho médio), passaram por uma restauração, a fim de corrigir distorções causadas pelos sensores, resultando em três novas bandas com $15 \mathrm{~m}$ de resolução espacial. Posteriormente, foi aplicado um contraste linear em cada banda, auxiliando também numa melhora visual da imagem. Assim, a identificação das lavouras de café foi realizada pela classificação visual, a qual necessitou de trabalhos de campo para validação do mapeamento. No total, foram localizadas 94 áreas ocupadas pela cultura do café em todo município nos trabalhos de campo, e a partir das coordenadas coletadas com o GPS, estas foram delimitadas por meio da edição vetorial disponível no software, utilizando a composição colorida RGB, na sequência TM4, TM 5, TM3. 
Para o estudo da declividade e da altimetria do município, foram utilizadas curvas de nível eqUidistantes de 20 metros, originadas de imagens interferométricas orbitais adquiridas pela missão SRTM (Shuttle Radar Topography Mission), da NASA, cuja carta topográfica de referência é S24W54. O arquivo com as curvas de nível foi obtido por meio do software Global Mapper, o qual foi exportado para o SPRING como sendo um Modelo Numérico do Terreno (MNT). O mapa de classes de declividade foi, então, gerado, a partir de uma grade triangular (TINs), e foram determinadas, segundo modelo proposto por Lemos \& Santos (1984), as seguintes faixas de declividade: plano: 0 - 3\%; suave ondulado: 3 - $8 \%$; ondulado: 8 - 20\%; forte ondulado: 20 - $45 \%$.

Para o estudo da hipsometria, foi gerada no SPRING uma grade retangular, obtida a partir da grade triangular (TINs) e, com o recurso do Fatiamento, foram criadas cinco classes de altitude, determinadas pela prévia avaliação das cotas mínima e máxima da área de estudo: 260 a 300 m; 300 a $340 \mathrm{~m} ; 340$ a $380 \mathrm{~m} ; 380$ a $420 \mathrm{~m}$ e 420 a $480 \mathrm{~m}$ de altitude.

A partir do mapa escaneado e georreferenciado de Levantamento de Reconhecimento dos Solos do Estado do Paraná (1971), cuja escala aproximada é de 1/300.000, foi digitalizado o mapa de solos do município de Umuarama, resultando em quatro classes de solos, sendo que estas foram atualizadas segundo nomenclatura da Empresa Brasileira de Pesquisa Agropecuária - Embrapa (1999), resultando em: LVd: Latossolo Vermelho distrófico; PVd: Argissolo Vermelho distrófico; PVe: Argissolo Vermelho eutrófico e NVef: Nitossolo Vermelho eutroférrico.

Após gerar os planos de informações com os mapas temáticos de declividade, hipsometria e classes de solos, realizaram-se os cruzamentos desses planos de informações, com os resultados da localização e distribuição das áreas ocupadas pela cultura cafeeira, utilizando-se da Tabulação Cruzada disponível no SPRING, a qual permite o cruzamento de diferentes planos de informação. Tal ferramenta permitiu a quantificação das áreas de café nas diferentes classes de declive, altitude e solo.

\section{RESULTADOS E DISCUSSÃO}

Por meio de interpretação visual da imagem Landsat e aliado aos trabalhos de campo realizados no município de Umuarama-PR, foi possível realizar o mapeamento das lavouras cafeeiras. Na Figura 2, apresenta-se uma região da área de estudo, captada pelo sensor TM, do LANDSAT 5,

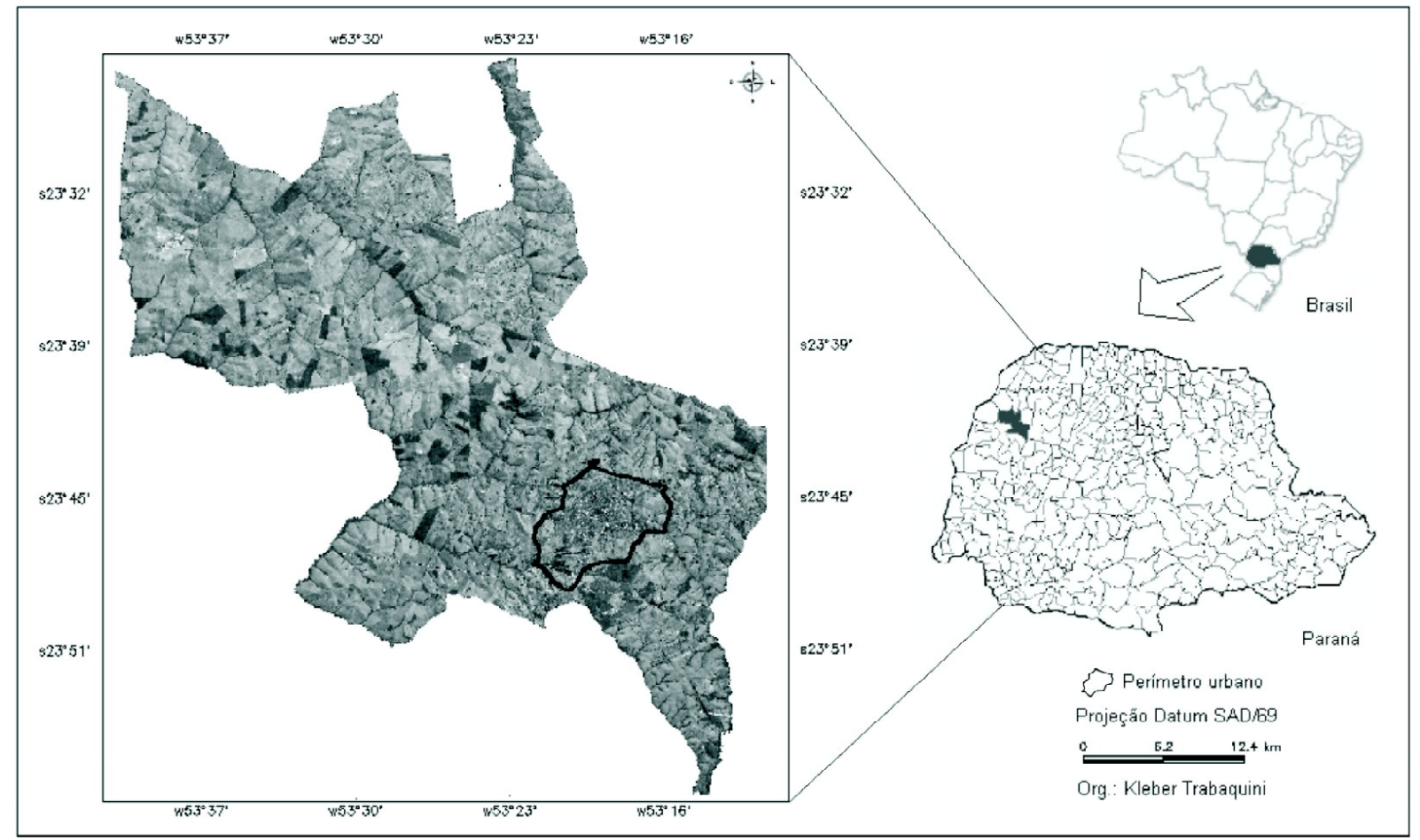

Figura 1 - Localização do município de Umuarama-PR ilustrado com a imagem LANDSAT 5/TM, na composição colorida RGB, na seqüência TM4, TM5, TM3. Órbita/Ponto: 223/76 - 223/77 e data de passagem em 02/07/2007. 
após passar por procedimentos de restauração e contraste, em composição colorida RGB, na sequência TM4, TM5, TM3. Nessa composição, a vegetação mais densa se revela nas cores mais escuras e a vegetação menos densa ou com menos massa verde (intercalada visualmente com solo), revela-se em tons mais claros. Nesse caso, pode-se observar que as lavouras cafeeiras apresentam uma grande variabilidade de resposta espectral, com diferentes tons de coloração. As áreas de floresta ou fragmento florestal apresentam uma tonalidade mais escura, em comparação à vegetação em estudo. Para Moreira (2001), fatores como espaçamento, idade, cultivar, face do relevo, tipo de solo e tratos culturais podem influenciar no comportamento espectral das lavouras de café.

A grande variabilidade espectral das lavouras cafeeiras pode, possivelmente, ser justificada, em virtude da alta reflectância do solo arenoso, a qual segundo Liu (2006) é causada pelos baixos teores de óxidos de ferro e da textura grossa do solo. A campo verificou-se que algumas lavouras são manejadas no sistema tradicional, onde as plantas não cobrem totalmente a superfície do solo, o que resulta numa maior contribuição do fator solo na reflectância do dossel. Ainda, segundo Moreira et al. (2004), lavouras plantadas no sistema tradicional têm uma resposta espectral muito influenciada pela componente solo. A localização e a distribuição das áreas cafeeiras são mostradas no mapa temático gerado pela classificação visual que identificou 607 ha de lavoura cafeeira (Figura 3). Segundo levantamentos do Instituto Brasileiro de Geografia e Estatística (IBGE) de 2007, o município de Umuarama possui uma área de 635 ha de café, já, a Secretaria Estadual de Abastecimento (SEAB) quantificou 600 ha desta cultura no mesmo período. Mesmo havendo divergências entre os levantamentos efetuados pelos órgãos governamentais, o resultado apresentado neste trabalho pode ser considerado de grande valia, se levado em consideração que existe um erro de aproximadamente $4 \%$ em relação aos dados do IBGE e $1 \%$ aos da SEAB.

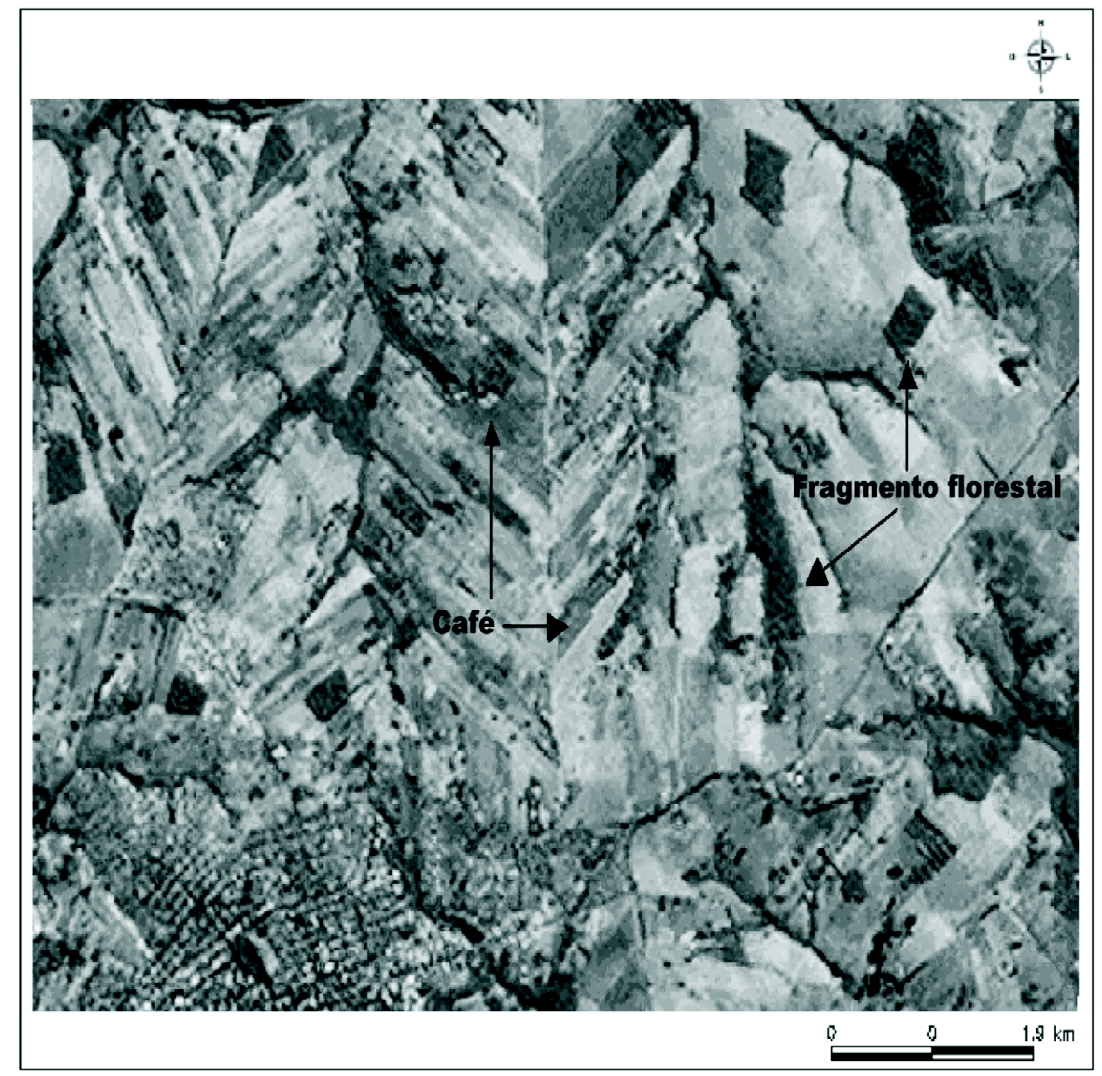

Figura 2 - Imagem do satélite LANDSAT 5/TM, com data de passagem em 02/07/2007 e órbita ponto 223/76 - 223/77, em composição colorida RGB, na sequência TM4, TM5, TM3, restaurada e com realce, destacando as classes de café e fragmento florestal no município de Umuarama-PR. 


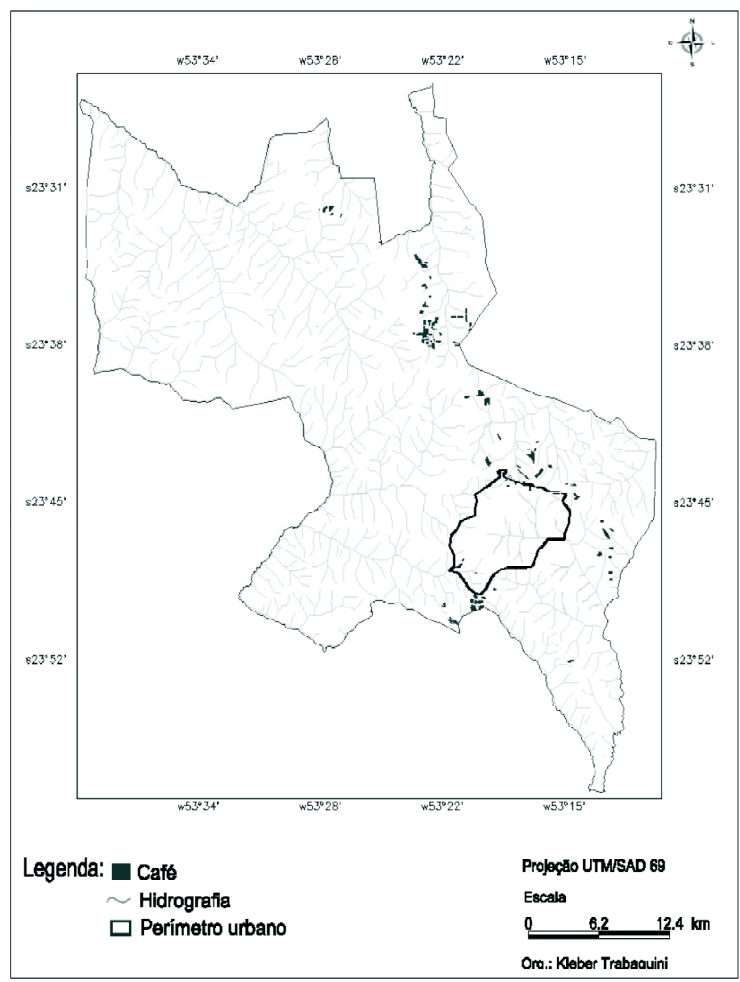

Figura 3 - Mapa de localização e distribuição das lavouras cafeeiras do município de Umuarama-PR, gerado a partir da classificação visual da imagem LANDSAT 5/TM, com data de passagem em 02/07/2007 e órbita/ponto 223/76 - 223/77.

Grande parte dos levantamentos agrícolas são realizados por meio de informações coletadas por agentes técnicos e dados econômicos como financiamentos, entrevistas com produtores, vendas de insumos e fertilizantes, entre outros, o que os tornam resultados de baixa confiabilidade (Ippoliti-Ramilo et al., 1999). Sendo assim, os resultados de área plantada com café obtido por essa metodologia, tornam-se uma fonte confiável de consulta.

A partir da grade triangular (TINs) gerada pelas curvas de nível equidistantes de 20 metros, foi gerado o mapa hipsométrico do município de Umuarama-PR, onde o ponto de menor altitude foi de 260 metros e o de maior altitude de 480 metros (Figura 4). Na Tabela 1 (a) demostrase que $62 \%$ desse município apresentam altitude entre 340 a 420 m. Utilizando a ferramenta de Tabulação Cruzada, tornou-se possível o cruzamento dos dados de altitude com os dados de distribuição das lavouras cafeeiras, verificando que $71,5 \%$ dessas lavouras estão localizadas em altitudes de 420 a $480 \mathrm{~m}$, seguido da classe 380 a $420 \mathrm{~m}$ com $28 \%$ dos cafeeiros e uma pequena parcela de $0,5 \%$ na classe 340 a $380 \mathrm{~m}$. Outra característica que pode-se observar ainda nessa tabela, é que abaixo dos 340 m não foi constatada a existência de cafezais, pois, no inverno, essas áreas de menor altitude acumulam o ar frio das encostas, possibilitando a ocorrência de geadas e possíveis danos às plantas.

Podemos observar ainda na Tabela 1 que as lavouras estão predominantemente instaladas nos patamares de maior altitude desse município, relacionado, principalmente, a ocorrência de temperaturas mais amenas em maiores altitudes. Segundo Malavolta (2000), a altitude é um dos fatores que afetam a qualidade da bebida, sendo que o café cultivado em maiores altitudes amadurece mais lentamente, possivelmente resultando numa bebida de melhor qualidade. A altitude deve ser levada em consideração quando na instalação da cultura, pois em diversas pesquisas como as de Silva et al. (2007) e Silva et al. (2009), os autores a citam, como fator importante na qualidade de bebida do café.

Podemos observar na Tabela 2 (a), que o relevo suave ondulado, referente à classe 3 a $8 \%$ de declividade, está presente em $54 \%$ do território desse municipio, seguido do relevo plano e ondulado, com 26 e 19,95\%, 
respectivamente. $\mathrm{O}$ relevo forte ondulado representa uma inexpressiva parcela desse terriório, com 0,05\% (Figura 5). Quanto a ocupaçao das lavouras cafeeiras, 62\% destas estão localizadas, predominantemente, sobre o tipo de relevo suave ondulado, ou seja, de 3 a $8 \%$ de declividade, seguido de $29 \%$ de lavouras sobre relevo plano e $9 \%$ sobre relevo ondulado. Não foram constatadas lavouras cafeeiras sobre o dominio do relevo forte ondulado (Tabela 2, b).

A declividade do terreno constitui-se em uma das características físicas que podem influenciar numa

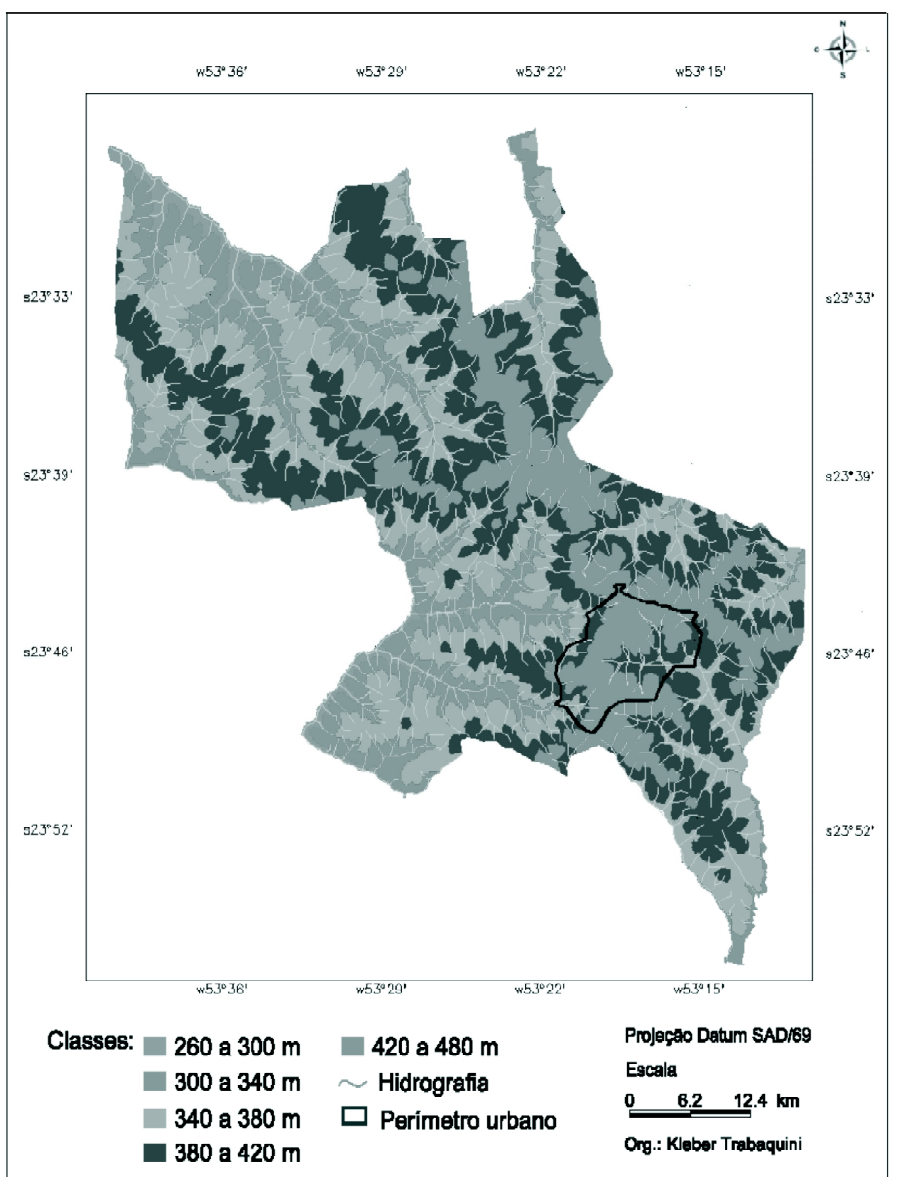

Figura 4 - Mapa Hipsométrico do município de Umuarama-PR, gerado a partir de dados SRTM.

Tabela 1 - Quantificação das classes de altitude no município de Umuarama-PR (a), e localização de lavouras cafeeiras segundo as classes de altitude (b).

\begin{tabular}{ccccc}
\hline Classes de Altitude & \multicolumn{2}{c}{ Umuarama (a) } & \multicolumn{2}{c}{ Lavoura Cafeeira (b) } \\
\hline metros & ha & $\%$ & ha & 0 \\
\hline 260 a 300 & 4.200 & 3 & 0 & 0 \\
300 a 340 & 20.200 & 18 & 0 & 0,5 \\
340 a 380 & 38.500 & 31 & 3 & 169 \\
380 a 420 & 38.500 & 31 & 435 & 71,5 \\
420 a 480 & 21.100 & 17 & 607 & 100 \\
\hline Total & 122.500 & 100 & &
\end{tabular}

Ciênc. agrotec., Lavras, v. 35, n. 1, p. 35-44, jan./fev. 2011 
produção rentável de café. Para Caramori et al. (2001) e Matiello et al. (2005), a lavoura cafeeira deve ser implantada em terrenos com declividade superior a 5\%, fazendo com que o ar frio escoe pelas encostas, diminuindo os riscos de incidência e danos causados pelas geadas e também favorecendo a boa drenagem do solo. Além disso, o relevo suave ondulado permite o manejo e práticas mecanizáveis desde o plantio até a colheita, o que reduz bastante o custo de produção da lavoura e possibilita também a exploração da atividade em grande escala. Porém, 29\% das lavouras cafeeiras de Umuarama estão situadas entre 0 a $3 \%$ de declividade, o que não é indicado segundo a literatura, pois esse relevo não favorece o escoamento do ar frio e a drenagem da água no solo.

No relevo ondulado, que compreende o intervalo de 8 a $20 \%$ de declividade, foram encontrados $9 \%$ das lavouras e no relevo forte ondulado, 20 a $45 \%$ de declividade, não foram localizadas plantações de café.

Tabela 2 - Quantificação das classes de declividade no município de Umuarama - PR (a), e localização das lavouras cafeeiras segundo as classes de relevo (b).

\begin{tabular}{|c|c|c|c|c|c|}
\hline \multicolumn{2}{|c|}{ Classes de Declividade } & \multicolumn{2}{|c|}{ Umuarama (a) } & \multicolumn{2}{|c|}{ Lavoura Cafeeira (b) } \\
\hline Classes & Declive & ha & $\%$ & ha & $\%$ \\
\hline Plano & 0 a $3 \%$ & 33.300 & 26 & 178 & 29 \\
\hline Suave ondulado & 3 a $8 \%$ & 65.630 & 54 & 376 & 62 \\
\hline Ondulado & 8 a $20 \%$ & 23.500 & 19,95 & 53 & 9 \\
\hline Forte ondulado & 20 a $45 \%$ & 70 & 0,05 & 0 & 0 \\
\hline \multicolumn{2}{|c|}{ Total } & 122.500 & 100 & 607 & 100 \\
\hline
\end{tabular}

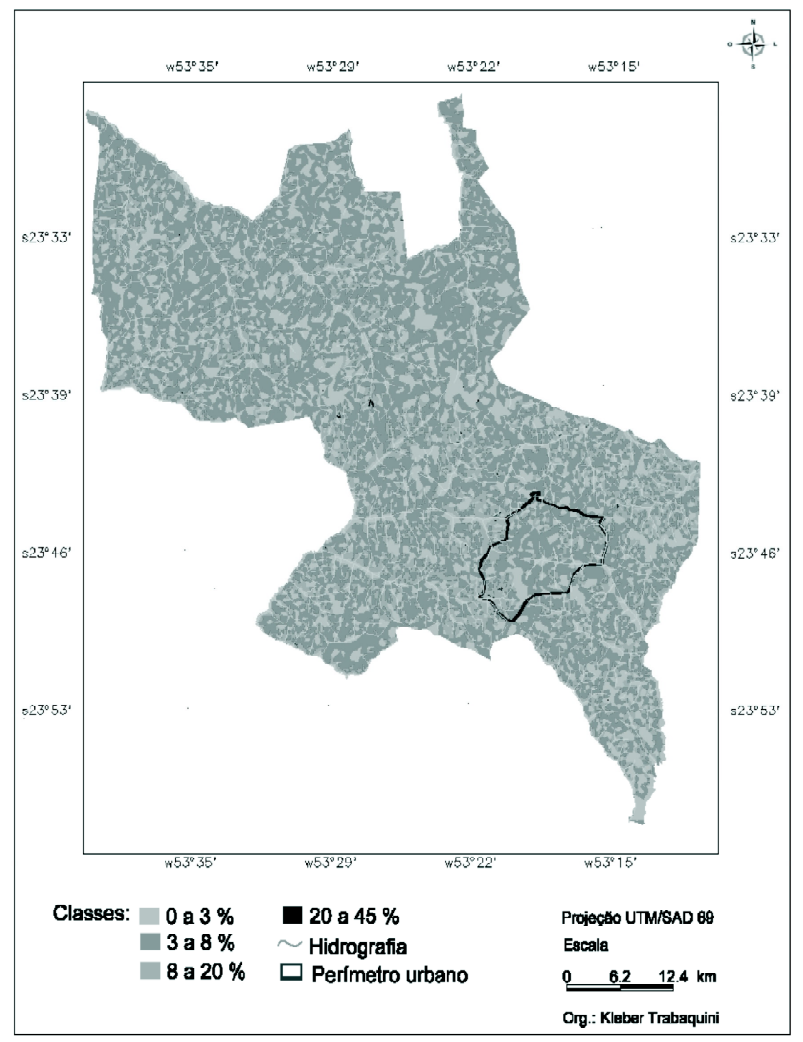

Figura 5 - Mapa de Declividade do município de Umuarama-PR, gerado a partir de dados SRTM. 
Analisando a Tabela 3 (a), onde são descritas as quatro classes de solos mapeadas em todo o território de Umuarama, pode-se constatar que o Latossolo Vermelho distrófico (LVd) é predominante, ocorrendo em $56 \%$ da área de estudo (Figura 6). Ainda na Tabela 3 (b), pode-se observar que $89 \%$ das lavouras cafeeiras estão localizadas preferencialmente sobre a classe de solo Latossolo Vermelho distrófico (LVd).
Normalmente, a classe Latossolo Vermelho distrófico (LVd) ocorre em locais de relevo plano ou suavemente ondulado, com alta profundidade efetiva. Nessa região, são caracterizados por apresentarem textura arenosa, baixos teores de matéria orgânica, baixo armazenamento de água e com teores de argila inferiores a $15 \%$; consequentemente, um solo deficiente em nutrientes e predisposto a altas taxas de processos erosivos

Tabela 3 - Quantificação das classes de solos no município de Umuarama-PR (a), e localização das lavouras cafeeiras segundo as classes de solo (b).

\begin{tabular}{ccccc}
\hline \multicolumn{1}{c}{ Classes de Solo } & \multicolumn{2}{c}{ Umuarama (a) } & \multicolumn{2}{c}{ Lavoura Cafeeira(b) } \\
\hline Solo & ha & $\%$ & ha & $\%$ \\
\hline LVd - Latossolo Vermelho distrófico & 68.600 & 56 & 540 & 89 \\
PVd - Argissolo Vermelho distrófico & 26.100 & 21 & 25 & 4 \\
PVe - Argissolo Vermelho eutrófico & 27.120 & 22,4 & 42 & 7 \\
\hline NVef - Nitossolo Vermelho eutroférrico & 680 & 0,6 & 0 & 0 \\
\hline Total & 122.500 & 100 & 607 & 100 \\
\hline
\end{tabular}

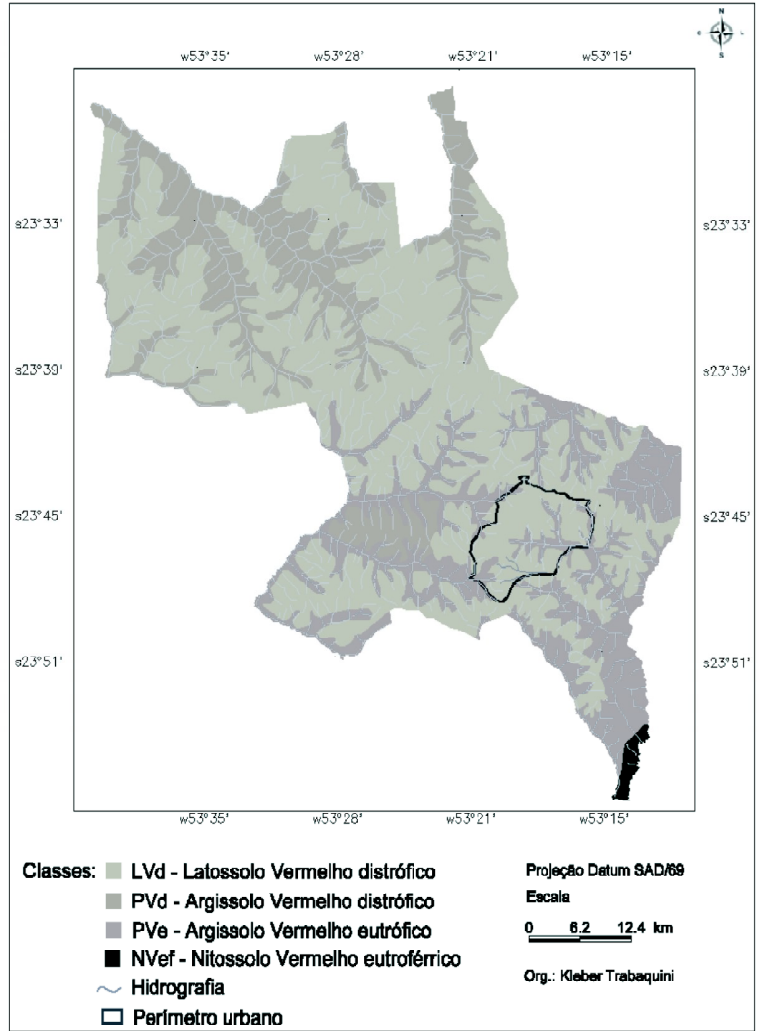

Figura 6 - Mapa de Solos do município de Umuarama-PR gerado a partir do levantamento de reconhecimento dos solos do estado do Paraná (1971). 
(Prado, 2001). Segundo Fidalski (1997), o cultivo sucessivo e o revolvimento excessivo desses tipos de solos, os quais são encontrados em grandes proporções na formação arenito Caiuá, na região noroeste do estado do Paraná, predispõe às altas taxas de erosão, de compactação e de perdas de matéria orgânica, resultando na degradação física, química e biológica dos mesmos, necessitando de manejo adequado, como adubação, calagem e implantação de terraços. Já, a classe dos Argissolos, os quais servem de substrato para o restante das lavouras cafeeiras, são encontrados em relevo ondulado; possuem baixa fertilidade natural, contém teores de óxidos de ferro inferiores a $15 \%$ e são altamente suscetíveis à erosão.

Outra característica importante que deve ser relacionada aos tipos de solos é de que as lavouras cafeeiras situadas em solos arenosos apresentam normalmente uma maturação mais precoce dos frutos, quando comparadas às situadas em solos argilosos (Silva et al., 2007). Informação esta que se torna necessária no manejo da cultura, principalmente no planejamento da colheita.

\section{CONCLUSÕES}

As imagens LANDSAT 5/TM, após passarem por procedimentos de restauração e contraste em composição colorida RGB, na sequência TM4, TM5, TM3, possibilitaram maior facilidade na execução da classificação visual e consequente identificação e mapeamento das lavouras cafeeiras no município de Umuarama, com alta precisão, aproximando-se dos dados de levantamentos agropecuários efetuados por órgãos governamentais. As lavouras de café do município de Umuarama encontramse, em sua grande maioria, em situação favorável quanto aos fatores físicos do ambiente, como declividade e hipsometria. Quanto às classes de solos, verificou-se que $89 \%$ das lavouras cafeeiras estão localizadas sobre Latossolo Vermelho distrófico (LVd), de textura arenosa e com alta profundidade efetiva, porém com baixa fertilidade natural e elevada predisposição a processos erosivos.

\section{AGRADECIMENTOS}

À CAPES, pela concessão da bolsa de estudos durante a realização deste trabalho.

\section{REFERÊNCIAS BIBLIOGRÁFICAS}

BORGES, V.P.; OLIVEIRA, A.S.de; SILVA, B.B.da. Mapeamento e quantificação de parâmetros biofísicos e radiação líquida em área de algodoeiro irrigado. Ciência e Agrotecnologia, Lavras, v. 34, n. 2, p. 485-493, mar./ abr. 2010.
CAMPOS, S.; SILVA, M.; PIROLI, L.; CARDOSO, L.G.; BARROS, Z.X. Evolução do uso da terra entre 1996 e 1999 no município de Botucatu-SP. Engenharia Agrícola, v.24, n.1, p.211-218, 2004.

CARAMORI, P.H.; CAVIGLIONE, J.H.; WREGE, M.S.; GONÇALVES, S.L.; FARIA, R.T.; SERA, T.; CHAVES, J.C.D.; KOGUISHI, M.S. Zoneamento de riscos climáticos para a cultura de café (Coffea arabica L.) no estado do Paraná. Revista Brasileira de Agrometeorologia, Passo Fundo, v.9, n.3, p.486-494, 2001.

\section{EMPRESA BRASILEIRA DE PESQUISA} AGROPECUÁRIA. Sistema brasileiro de classificação de solos. Rio de Janeiro, 1999.

EPIPHANIO, J.C.N.; GLERIANI, J.M.; FORMAGGIO, A.R.; RUDORFF, B.F.T. Índices de vegetação no sensoriamento remoto da cultura do feijão. Pesquisa Agropecuária Brasileira, Brasília, v.31, n.6, p.445-454, jun. 1996.

EPIPHANIO, J.C.N.; LUIZ, A.J.B.; FORMAGGIO, A.R. Estimativas de áreas agrícolas municipais, utilizando sistema de amostragem simples sobre imagens de satélite. Bragantia, Campinas, v.61, n.2, p.187-197, 2002.

FIDALSKI, J. Fertilidade do solo sob pastagens, lavouras anuais e permanentes na região Noroeste do Paraná. Revista Unimar, Maringá, v.19, p.853-861, 1997.

\section{INSTITUTO AGRONÔMICO DO PARANÁ. Cartas} climáticas do estado do Paraná. Londrina, 2000. 45p.

INSTITUTO BRASILEIRO DE GEOGRAFIA E ESTATÍSTICA. Produção agrícola municipal 2006. Brasília, 2006. Disponível em: <http:// iwww.sidra.ibge.gov.br/ $>$. Acesso em: 2 abr. 2008.

IPPOLITI-RAMILO, G.A.; EPIPHANIO, J.C.N.; SHIMABUKURO, Y.E.; FORMAGGIO, A.R. Sensoriamento remoto orbital como meio auxiliar na previsão de safras. Agricultura em São Paulo, São Paulo, v.46, n.1, p.89-101, 1999.

LEMOS, R.C.; SANTOS, R.D. Manual de descrição e coleta de solo no campo. Campinas: Sociedade Brasileira de Ciência do Solo; Serviço Nacional de Levantamento e Conservação de Solos, 1984. 45p. 
LIU, W.T.H. Aplicações de sensoriamento remoto. Campo Grande: UNIDERP, 2006. 908p.

MALAVOLTA, E. História do café no Brasil: agronomia, agricultura e comercialização. São Paulo: Agronômica Ceres, 2000. 464p.

MATIELLO, J.B.; SANTIAGO, R.; GARCIA, A.W.R.; ALMEIDA, S.R.; FERNANDES, D.R. Cultura de café no Brasil: novo manual de recomendações. Rio de Janeiro: MAPA/PROCAFE, 2005. 387p.

MAURINA, A.C.; BUBLITZ, U. Manejo integrado de solos e água: solos derivados do Arenito Caiuá. Curitiba: EMATER-PR/SERT, 2001. 36p.

MOREIRA, M.A. Fundamentos do sensoriamento remoto e metodologias de aplicações. São José dos Campos: INPE, 2001. 250p.

MOREIRA, M.A.; ADAMI, M.; RUDORFF, B.F.T. Análise espectral e temporal da cultura do café em imagens Landsat. Pesquisa Agropecuária Brasileira, Brasília, v.39, p.223-231, 2004.

NEPOMUCENO, A.N.; SILVA, I.C. Caracterização de sistemas silvipastoris da região noroeste do Estado do Paraná.Floresta, Curitiba, v.39, n.2, p.279-287, abr.jun. 2009.

PRADO, H. Solos do Brasil: gênese, morfologia, classificação e levantamento. 2.ed. rev. e ampl. Piracicaba: ESALQ, 2001.
RESENDE, M.; CURI, N.; REZENDE, S.B.D.; CORREA, G.F. Pedologia: base para distinção de ambientes. Viçosa, MG: NEPUT, 1995. 304p.

SANCHES, I.D.; EPIPHANIO, J.C.N.; FORMAGGIO, A.R. Culturas agrícolas em imagens multitemporais do satélite Landsat. Agricultura, São Paulo, v.52, n.1, p.8396, jan./jun. 2005.

\section{SECRETARIA DE ESTADO DAAGRICULTURAE} ABASTECIMENTO. Safra 2006/2007. Disponível em: 4http://www.seab.pr.gov.br/arquivos/File/PDF/ ISAFRA_2006.pd $>$. Acesso em: 26 fev. 2008.

SILVA, F.M.; SOUZA, Z.M.; FIGUEIREDO, A.A.P.; MACHADO, R.V. Variabilidade espacial de atributos químicos e de produtividade na cultura do café. Ciência Rural, v.37, n.2, p.401-407, 2007.

SILVA, M.C.S.; CASTRO, H.A.O.; FARNEZI, M.M.M.; PINTO, N.A.V.D.; SILVA, E.B. Caracterização química e sensorial de cafés da chapada de minas, visando determinar a qualidade final do café de alguns municípios produtores. Ciência e Agrotecnologia, Lavras, v.33, n. Edição especial, p.1782-1787, 2009.

XAVIER, A.C.; VETTORAZZI, C.A.; MACHADO, R.E. Relação entre índice de área foliar e frações de componentes puros do modelo linear de mistura espectral, usando imagens ETM+/Landsat. Engenharia Agrícola, v.24, n.2, p.421-430, 2004. 